\title{
Research on corrosion mechanism of overhead conductor
}

\author{
Wei Zheng ${ }^{1, *}$, Xizhong $\mathrm{Li}^{1}$, Zhongkai $\mathrm{Xu}^{1}$, Zhuochen $\mathrm{Jin}^{1}$ and Yang Liu ${ }^{1}$ \\ ${ }^{1}$ State Grid Yingkou Electric Power Supply Co., Ltd., Yingkou, Liaoning
}

\begin{abstract}
During the operation of overhead conductors, conductors are corroded to varying degrees by the smoke and dust, harmful gases from factories around the lines, or in corrosive salt fog atmosphere in coastal and island areas, as well as humid and hot weather conditions. In this paper, through the study of the corrosion mechanism of the conductor, the types of the corrosion are analyzed, and the factors leading to the corrosion and the corrosion process are analyzed by selecting the steel cored aluminum stranded wire, so as to provide theoretical basis for the development of anti-corrosion wire and the judgment of corrosion detection.
\end{abstract}

\section{Purpose and significance}

Transmission line is the main part of overhead line, which plays the role of transmitting electric energy from power supply to power load center, and occupies an extremely important position in the transmission line.At present, ACSR is the most widely used in overhead transmission line. The application and production of this kind of conductor are relatively mature, and it is widely used. However, with the development needs of the power industry and the progress of technology, many countries in the world have begun to widely use all kinds of aluminum alloy wires on transmission lines, mainly including aluminum alloy cored aluminum strand (ACAR), aluminum alloy steel cored wire (AACSR), all aluminum alloy strand (AAAC), etc. According to the linear energy of alloy, it can be divided into medium strength aluminum alloy wire, high strength aluminum alloy wire and heat-resistant series aluminum alloy wire. With the rapid development of China's economy and the acceleration of industrialization process, acid rain, haze and other issues are becoming increasingly prominent ${ }^{[1-2]}$. In China's coastal and heavily polluted industrial areas and other atmospheric corrosive areas, the existence of high concentration of salt, acid gas and dust in the air easily erode the steel core wire and aluminum wire of overhead conductor, reduce the overall tensile strength of the conductor, reduce the effective transmission cross section of the conductor, and even appear the phenomenon of broken strand and broken wire of steel core and aluminum wire, which has an impact on the service life of the line ${ }^{[3-5]}$. According to the relevant statistics of the power operation Department, the actual service life of the long-term running conductor in this heavy corrosion environment will be reduced to 10 years or even less than 5 years, which poses a serious challenge to the long-term safe and stable operation of power grid.In this paper, through the research on the mechanism of conductor corrosion, the types of conductor corrosion and the factors that can easily lead to corrosion are analyzed. It provides a solid guarantee for the technical innovation of overhead conductor anticorrosion, improving the corrosion resistance of active conductor, and ensuring the safe operation of overhead line.

As the main carrier of power transmission line, the importance of overhead wire is self-evident, and steel core as a load-bearing part plays an important role in controlling the safe distance between the line and the ground, bearing various loads and ensuring the safe operation of the line. There is no relevant report and report on Corrosion Detection in China, and relevant institutions have not carried out research on it. The serious corrosion and even broken wire accident of medium frequency transmission line has aroused the attention of power operation and maintenance departments. In order to clearly understand the corrosion state of wires, the power department puts forward the demand of corrosion detection. The development of corrosion detection methods and equipment has become an industry in urgent need of development.

\section{Corrosion type of conductor}

\subsection{Corrosion mechanism of wire}

In the course of service, the overhead conductors are corroded to different degrees due to the corrosive atmosphere of smoke and harmful gas emitted from factories around the lines, corrosive salt fog atmosphere in coastal and island areas, and humid and hot weather conditions. According to different causes of wire corrosion, wire corrosion can be divided into chemical corrosion, electrochemical corrosion and interstitial corrosion.

\footnotetext{
* Corresponding author: 773221288@qq.com
} 


\subsection{Chemical corrosion}

The direct chemical reaction between the gas and the atmosphere is the corrosion of the conductor. For ACSR, a continuous and dense oxide film is formed on the surface of ACSR after reaction with oxygen. The film is insoluble in water, and generally exists stably in the aqueous solution with $\mathrm{pH}$ of $4 \sim 9$ except for strong acid and alkali, which can play a certain role in passivation and protection of aluminum wire surface corrosion. As a load-bearing part of the galvanized steel core wire, the oxide structure of zinc and iron formed after reaction with oxygen is loose and easy to fall off, and continue to infiltrate and diffuse into the interior continuously, causing material failure. Other harmful gases or ions in the atmosphere, such as $\mathrm{Cl}^{-}, \mathrm{CO}_{3}{ }^{2-}$, free alkali or sulfuric acid, are easy to react with metals or other oxides to accelerate metal corrosion. For example, $\mathrm{Cl}^{-}$in atmospheric corrosive medium is easy to adsorb on the surface of the oxide film of aluminum strand wire, and reacts with the oxide film, resulting in local thinning and penetration, thus causing corrosion of aluminum wire.

\subsection{Electrochemical corrosion}

Electrochemical corrosion refers to the corrosion of metal materials in the electrolyte by galvanic action. When a galvanic cell is composed of two metals and electrolytes with different electrode potentials, the metal with larger negative electrode potential is more likely to be corroded. The greater the electrode potential difference between the two metals, the stronger the electrochemical corrosion, and the higher the temperature and humidity, the more serious the metal corrosion. The natural electrode potential of the metals in salt water is arranged in the order of $\mathrm{Zn}, \mathrm{Al}$ and $\mathrm{Fe}$, which is different from the standard electrode potential values of $\mathrm{Al}(-1.66 \mathrm{v}), \mathrm{Zn}(-0.76 \mathrm{v})$ and $\mathrm{Fe}(-0.44 \mathrm{v})$ Therefore, the electrochemical corrosion between zinc and inner aluminum occurs first. When the zinc layer which acts as anode in the corrosion couple corrodes the steel wire, the micro cell will be formed between the aluminum and steel to corrode the aluminum conductor. That is to say, in the early service period of ACSR, the zinc coating acts as an anode to protect the steel core and aluminum conductor. After the zinc coating is damaged, the aluminum conductor becomes the anode, which accelerates the corrosion of aluminum conductor. In practical use, the zinc coating has good protection in dry air, but its corrosion protection effect is significantly reduced in humid marine atmosphere such as coastal environment.

\subsection{Interstitial corrosion}

Interstitial corrosion refers to the corrosion caused by the corrosive atmosphere in the atmosphere and the dielectric such as rain water entering the conductor through the gap between single wires. It still belongs to the category of chemical corrosion and electrochemical corrosion in essence.
For the commonly used ACSR, the atmospheric corrosion of ACSR is different from that of other metal materials because of its composite structure. The inner layer of aluminum strand is covered by the outer layer of aluminum strand, the erosion of the material surface by rain is reduced, the corrosion products continue to deposit, and the existence time of liquid film is prolonged, thus increasing the electrochemical corrosion time; the aluminum strand of the wire contacts with the aluminum strand to form a gap, which will cause interstitial corrosion; while when the aluminum strand contacts with the steel core, the galvanic corrosion between dissimilar metals will be formed due to different potentials.

\section{Research on Corrosion of ACSR}

\subsection{Corrosion of aluminum strands}

When the aluminum strands of ACSR wires are exposed to the atmospheric environment, a continuous and dense hydrated alumina film $\left(\mathrm{Al}(\mathrm{OH})_{3}\right)$ is formed on the surface of ACSR wires, which is closely bonded with the matrix. The oxide film is insoluble in water, and is generally stable in aqueous solution with $\mathrm{pH}$ of $4 \sim 9$ except strong acid and strong alkali. However, in a certain concentration of $\mathrm{Cl}^{-}$solution (such as $\mathrm{NaCl}$ solution), it will accelerate the destruction of the oxide film and eventually lead to the corrosion of aluminum. When $\mathrm{HSO}_{3}{ }^{-}$and $\mathrm{Cl}^{-}$coexist in corrosive medium, the aluminum strands show local corrosion, mainly pitting corrosion, and $\mathrm{Cl}^{-}$is easy to form pitting corrosion source. Firstly, $\mathrm{Cl}^{-}$in the corrosive medium is adsorbed on the surface of the oxide film, which accelerates the hydrolysis of the oxide film and reacts with the hydrolysate to form a series of basic chloride salts.

Firstly, $\mathrm{Cl}^{-}$in the corrosive medium is adsorbed on the surface of the oxide film, which accelerates the hydrolysis of the oxide film and reacts with the hydrolysate to form a series of basic chloride salts.

At the same time, $\mathrm{HSO}_{3}{ }^{-}$is hydrolyzed to form $\mathrm{SO}_{3}{ }^{2-}$, and $\mathrm{SO}_{3}{ }^{2-}$ is oxidized to form $\mathrm{SO}_{4}{ }^{2-}$. Then, $\mathrm{Cl}$ in aluminum chloride is replaced by $\mathrm{SO}_{4}{ }^{2-}$ to form aluminum sulfate, basic sulfate and hydrate thereof

Corrosion reaction often produces pitting pits at the weak part of the oxide film and spreads to the periphery and depth until the corrosion medium penetrates the oxide layer and directly acts on the aluminum strands. Electrochemical corrosion of aluminum strands occurs under the action of ions in solution, resulting in a large number of pitting pits, which expand along the circumferential direction of aluminum strands and form a continuous corrosion product layer. Meanwhile, pitting pits continue to expand radially inward along the strands, resulting in a gradual increase in the thickness of corrosion layer.

\subsection{Corrosion of Hot Galvanized Steel Core}

The corrosion of galvanized steel core in ACSR conductor is mainly the corrosion of galvanized layer. 
According to the structural analysis of the corrosion layer on the surface of galvanized steel core wire, the corrosion of galvanized layer firstly forms pitting corrosion on the galvanized layer, and then the corrosion pit extends to the periphery and depth direction, and the main corrosion mechanism is electrochemical corrosion.

\subsection{Corrosion of steel-reinforced aluminum stranded wire}

The corrosion behavior of ACSR is mainly the result of local pitting of oxide film and electrochemical corrosion between strands. The ACSR (outer aluminum wire and inner steel core), which is commonly used for power transmission wires, has a multi-stranded structure, so corrosive substances such as chloride ions $\left(\mathrm{Cl}^{-}\right)$are easy to exist in the gaps between the strands, which may lead to corrosion. And the corrosion in the gap is difficult to detect and evaluate visually. In addition, the smoke from industrial waste treatment facilities will also lead to corrosion of the wire surface, and the dust contained in the smoke will also adhere to the wire and cover the surface, so the corrosion state of the wire can be evaluated intuitively through the wire surface state.

As for the electrochemical corrosion between conductor strands, some studies show that the order of increasing natural electrode potential of metals in saline solution is $\mathrm{Zn}, \mathrm{A} 1$ and Fe. For ACSR conductor, because $\mathrm{NaCl}+\mathrm{NaHSO}_{3}$ solution remains between strands, the galvanic cell is formed between the galvanized layer on the surface of steel core wire and the inner aluminum strand, and electrochemical corrosion occurs. $\mathrm{Zn}$ is the anode, which is corroded, while Al is protected. This may be the reason why the corrosion rate of galvanized layer is obviously higher than that of inner and outer aluminum strands, while the corrosion degree of outer aluminum strands is greater than that of inner aluminum strands. When the galvanized layer is corroded, a new microcell will be formed again between the inner aluminum strand and the steel core wire. At this time, the inner aluminum strand is the anode, which accelerates the corrosion while the steel core wire is protected. It can be assumed that if the corrosion time of ACSR wires in simulated atmospheric corrosion medium exceeds $1440 \mathrm{~h}$, the corrosion degree of inner aluminum strands will probably exceed that of outer aluminum strands.

In the early stage of corrosion, local pitting corrosion was formed on the surface of inner and outer aluminum strands and steel core wires, and then the corrosion extended to the surrounding and depth direction to form a continuous corrosion layer. As shown in figure 1. The corrosion products of ACSR are complex and diverse, including hydroxides of $\mathrm{Zn}$ and $\mathrm{Al}$, sulfate and compound salts of chloride. The EDS and X-ray fluorescence spectra of white junction crystals are given in Table 1, respectively. The results show that the composition of white junction crystal is mainly composed of $\mathrm{O}, \mathrm{Al}, \mathrm{Cl}$, and a small amount of other elements such as $\mathrm{Zn}$.

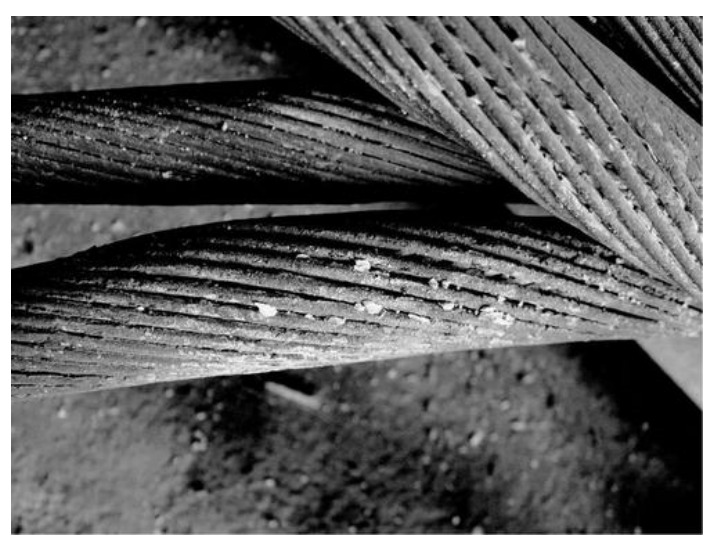

(a)Corrosion morphology and corrosion products of aluminum stranded wire

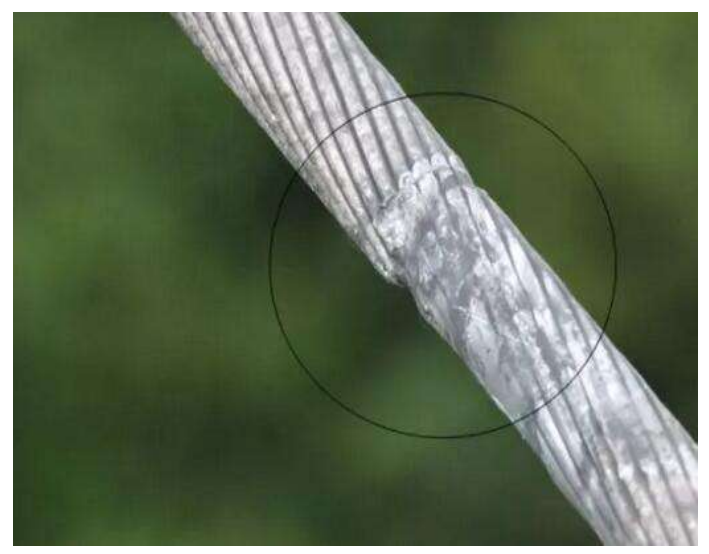

(b) Corrosion morphology of galvanized steel core wire

Figure 1. Photo of corrosion morphology of steel-cored aluminum stranded wire.

Table 1. X-ray fluorescence spectroscopic analysis of inner junction crystal of ACSR.

\begin{tabular}{|c|c|}
\hline Analytical elements & Mass percentage \\
\hline $\mathrm{O}$ & $52.3689 \%$ \\
\hline $\mathrm{Al}$ & $23.9697 \%$ \\
\hline $\mathrm{Cl}$ & $22.4574 \%$ \\
\hline $\mathrm{Zn}$ & $1.0830 \%$ \\
\hline $\mathrm{Si}$ & $0.0540 \%$ \\
\hline $\mathrm{Fe}$ & $0.0531 \%$ \\
\hline $\mathrm{Br}$ & $0.0079 \%$ \\
\hline $\mathrm{Ca}$ & $0.0060 \%$ \\
\hline
\end{tabular}

The corrosion atmosphere, humidity, temperature, wind speed and other service environment around the overhead conductor will affect the corrosion degree and service life of the conductor. In many environmental factors, humidity and atmospheric composition are two key factors. LY12 aluminum alloy with $1 \mathrm{mg} / \mathrm{dm}^{2} \mathrm{Cl}^{-}$on the surface almost does not corrode in the atmosphere with relative humidity of $70 \%$, and obvious pitting corrosion occurs when the relative humidity is $70 \%$. In atmospheric corrosive environment, $\mathrm{SO}_{2}$ is generally considered as one of the most serious corrosive gases, 
which can aggravate the corrosion behavior of most metals. The corrosion of overhead conductors is not only related to the environmental characteristics, but also closely related to the service state characteristics of conductors, such as operating temperature, tension, fretting wear between wires, strong electromagnetic field, etc. The overhead conductor is in tension stress state in the running state, and the stress will change under the influence of galloping and wind vibration. The synergistic effect of stress, atmospheric corrosion and operating temperature on the conductor will accelerate the corrosion damage of the conductor, and the corrosion fracture of the conductor under the stress may occur instantaneously with strong concealment. At the same time, wind-induced galloping and vibration lead to micro slip and alternating stress between the aluminum strands in the conductor during the operation of the conductor. The superposition effect of fretting wear, fatigue and atmospheric corrosion (fretting corrosion) will further aggravate the damage of the conductor.

The fracture of fretting corrosion aluminum strand starts from the fatigue crack under the wear spot. The crack under the wear surface promotes the fretting corrosion of aluminum strand by means of electrochemical reaction. The corrosion pits, holes and their propagation become the main causes of fretting damage and failure of ACSR under atmospheric corrosion. In addition, in the environment of strong electric field, lightning and other electromagnetic fields, the outer layer of overhead ground wire (conductor) is easy to be ablated by strong lightning current, which affects its corrosion resistance, but its mechanism remains to be further studied. At present, most of the steel cored aluminum strand put into use are still protected by hot-dip pure zinc coating. In coastal areas, heavy industrial pollution and other areas with strong corrosive environment, obvious corrosion usually occurs after 4-8 years, and its service life is less than 10 years, which is far from meeting the requirements of safe service life of transmission lines. Therefore, the exploration of new anti-corrosion technology of overhead conductors has become a key technical problem to improve the corrosion resistance of existing conductors, which has attracted more and more attention of cable enterprises and power users.

\section{Conclusion}

Based on the study of the corrosion mechanism of the conductor, this paper analyzes the types of the wire corrosion, the factors leading to the corrosion and the corrosion process, so as to provide a theoretical basis for the development of anti-corrosion wire and the judgment of corrosion detection.

\section{Acknowledgement}

Fund project: Science and technology project of State Grid: Key Technology of Development and Application of Anticorrosive Conductor (2018YF-29)

\section{References}

1. AN, N. Study on Conductor Corrosion and Protection of Transmission Line in Atmospheric Environment. North China Electric Power University, BeiJing. (2014)

2. Li, B.,Meng,X.B., Wang, G.L.Investigation and Analysis on the Corrosion of Overhead Conduction in the South Coastal Areas. J. Electric Wire \& Cable., 4: 6-9. (2018)

3. Zhou, S.L., Hu, X.L., Yue, Z.W. Chemical Analysis of Breaking Accident of $220 \mathrm{kV}$ Aluminum Conductor Steel Reinforced Cable. J. Corrosion \& Protection., 32(5) : 392-394. (2011)

4. Hu, Y.W., Hua, J.F.,Dang, P. Anti-corrosion Measurements of Overhead Conductors. J. Electric Wire \& Cable., 4: 12-14.(2017)

5. Zhu, Z.X., Chen, B.A., Zhang, Q.Corrosion Analysis and Protection Technology for Overhead Transmission Conductors. J. Electric Power., 49(5) : 8-13.F (2016)

6. Chen Y.X, Lin D.Y. Corrosion behavior of steel reinforced rare earth aluminum stranded wire. J. Electric power and electrical engineering, (2): 3235,2013 